\title{
The Interrelationships Between Brand and Channel Choice
}

\section{Citation}

Neslin, Scott, Kenshuk Jerath, Anand Bodapati, Eric T. Bradlow, John A. Deighton, Sonja Gensler, Leonard Lee, et al. "The Interrelationships Between Brand and Channel Choice." Marketing Letters 25, no. 3 (September 2014): 319-330.

\section{Published Version}

http://link.springer.com/article/10.1007\%2Fs11002-014-9305-2

\section{Permanent link}

http://nrs.harvard.edu/urn-3:HUL.InstRepos:14485590

\section{Terms of Use}

This article was downloaded from Harvard University's DASH repository, and is made available under the terms and conditions applicable to Open Access Policy Articles, as set forth at http:// nrs.harvard.edu/urn-3:HUL.InstRepos:dash.current.terms-of-use\#OAP

\section{Share Your Story}

The Harvard community has made this article openly available.

Please share how this access benefits you. Submit a story.

Accessibility 


\title{
The Interrelationships between Brand and Channel Choice
}

\author{
Scott A. Neslin \\ Tuck School of Business, Dartmouth College \\ Kinshuk Jerath \\ Columbia Business School, Columbia University \\ Anand Bodapati \\ Anderson School of Management, UCLA \\ Eric T. Bradlow \\ The Wharton School, University of Pennsylvania \\ John Deighton \\ Harvard Business School, Harvard University \\ Sonja Gensler \\ University of Münster \\ Leonard Lee \\ Columbia Business School, Columbia University \\ Elisa Montaguti \\ Management Department, University of Bologna \\ Rahul Telang \\ H.J. Heinz College, Carnegie Mellon University \\ Raj Venkatesan \\ Darden School of Business, University of Virginia \\ Peter C. Verhoef \\ Faculty of Economics and Business, University of Groningen \\ BI Norwegian Business School \\ Z. John Zhang \\ The Wharton School, University of Pennsylvania \\ March 2014 \\ 2013 Choice Symposium \\ Erasmus University, Noordwijk, The Netherlands
}




\section{Abstract \\ The Interrelationships between Brand and Channel Choice}

We propose a framework for the joint study of the consumer's decision of where to buy and what to buy. The framework is rooted in utility theory where the utility is for a particular channel/brand combination. The framework contains firm actions, the consumer search process, the choice process, and consumer learning. We develop research questions within each of these areas. We then discuss methodological issues pertaining to the use of experimentation and econometrics. Our framework suggests that brand and channel choices are closely intertwined, and therefore studying them jointly will reveal a deeper understanding of consumer decisionmaking in the modern marketing environment.

Keywords: brand choice, channel choice, learning, utility theory 


\section{The Interrelationships between Brand and Channel Choice}

Throughout the post-industrial era, consumers have been faced with the decision of choosing brands. Levi's or Wrangler? Apple or Samsung? The last decade has seen a proliferation of channels through which firms interact with customers. Levi's, Wrangler, as well as Apple and Samsung can be purchased online, in bricks-and-mortar stores, or through catalogs. Platform retailing arrangements that give brands direct access to consumers are also becoming increasingly popular, both offline, such as "stores within a store" (Jerath and Zhang 2010), and online, such as Amazon Marketplace. Thus, today's consumer must choose both a brand and a channel. The question is how brand and channel choices are interrelated. We advocate that this question presents an opportunity to learn in more depth how consumers make decisions in the modern marketing environment.

There has been much research on brand choice, dating at least to Kuehn and Rohloff (1967), continuing through Guadagni and Little (1983). See Russell (2014) for a history of the development of this field. Recently there has been a growing literature on channel choice (Thomas and Sullivan 2005; Valentini et al. 2011). However, to our knowledge there is little research that integrates brand and channel choice.

One might argue that channel and brand choice could just be studied separately. Yet, researchers have found that consumers make different choices depending on which channel they use (Danaher et al. 2003), that marketing induces consumers to switch channels (Ansari et al. 2008) and that brand and channel perceptions together determine purchase intentions (Dodds et al. 1991). This suggests that the two processes are intertwined. Certainly managers are concerned with how to manage their brands across channels. Therefore, while the field is not well- 
developed, we believe there is significant academic and managerial motivation for studying the interrelationships between brand and channel choice. In particular, our objectives are to:

- develop a framework for studying the interrelationships between channel and brand choice,

- utilize the framework to generate research topics, and

- discuss methodological challenges in researching channel/brand choice.

\section{A Framework for Studying the Interrelationships between Brand and Channel Choice}

\subsection{Description of Framework}

We derived our framework (Figure 1) deductively, drawing from economic utility theory, as well as inductively, drawing on "stories" of our own brand/channel choice experiences. The key elements of the framework are:

- Firms (retailers and manufacturers) provide brands and channels ( $\mathrm{F}$ in Figure 1).

- Consumers maximize utility over brand/channel combinations $\left(U_{b, c}\right)$.

- Consumers undertake information search (S) and subsequent choice (C).

- Consumers learn from search and previous choices (L).

- Consumers are constrained by budget, time, and information.

[Figure 1 Goes Here]

Firms define the marketing environment by stipulating the channels and brands available (e.g., Apple selling its brand through the Internet and company retail stores). Firms also take strategic and tactical marketing actions such as promotions and advertising. Finally, firms intercede directly in the consumer's choice process by providing services (e.g., in-store sales assistance, and personalized digital communications). 
The consumer's choice process begins when the consumer perceives a need, which could arise due to firm marketing activities, personal knowledge, or learning from the search process. The consumer also has characteristics such as psychographics and employs decision rules constrained by budget, time, and information regarding the product category and brand/channel utilities.

The consumer has an information set at time $t\left(I_{t}\right)$, which defines the utilities for various brand/channel combinations ( $U_{b, c, t}$, where $b=$ brand and $c=$ channel), as well as for the null option $\left(U_{0, t}\right)$ of not purchasing. These utilities are represented by lines above $I_{t}$ in Figure 1, where the thickness of the line represents the strength of preference for each brand/channel combination. The consumer may have no information when he or she starts the process: this would mean no lines above $I_{t}$.

Search is a critical aspect of shopping, articulated by Ratchford (1982) and more recently by Verhoef et al. (2007). Given the current set of brand/channel combinations, if a consumer feels that additional search would provide her with better information about the current choice set or more relevant choices, at reasonable "cost of search", she may decide to search more. After search, more lines appear as consumers form utilities for newly identified brand/channel combinations. In addition, utilities for previously identified alternatives may change. Therefore new lines appear above $I_{t+1}$, and those lines can have different thickness than the lines for $I_{t}$.

The search process continues iteratively wherein at any point the consumer may decide to conduct additional search or proceed to make a choice of which brand to buy in which channel. This may entail forward-looking judgment on the part of the consumer. A choice will be made only if at least one brand/channel utility exceeds the utility of the null option. After the choice is made, the consumer remembers (learns) utilities, general lessons on the desirability of various 
brands/channels, and how to go about evaluating them. This updated consumer knowledge is used when the next need arises.

We highlight four crucial aspects of the process: $\mathrm{F}$ for firm actions (either retailer or manufacturer); S for search; C for choice; and L for what is learned from feedback. We will use these letters to further illustrate the framework and to organize research questions.

\subsection{Illustrative "Stories"}

An effective way to illustrate our framework is to show how it can be used to represent various scenarios or "stories" of search/purchase. We discuss three stories, using the letters F, S, C, L to show when these components of the framework are relevant. We trace the utility development aspect of these stories in Figure 2. The purpose is to illustrate the framework, demonstrate its relevance, and show how brand and channel choice are intertwined.

[Figure 2 Goes Here]

Story \#1: Purchasing a Book at Amazon:

"I needed an econometrics text, and needed it fast. I knew the title, "STAT". I'm loyal to Amazon and if they had "STAT" (F), I'd just order it from them. Money was no object since my employer was paying for the book. But I know Amazon to be pretty inexpensive anyway. So I went online and navigated to Amazon to see if they had the book (S). They did and I bought it (C)."

Figure 2A shows that the consumer starts out with strong preference for buying STAT on Amazon $-U_{S T A T, A m a z o n, t}$ is the only brand/channel line before search and is thicker than the null option line. The consumer is unconstrained by budget but constrained by time. Since Amazon offers the desired book, the consumer is satisfied and purchases it.

\section{Story \#2: Showrooming}

"I needed a baby carrier. I had no idea what particular brand I wanted so I went to my local baby store, BabyLand (F), to see what they had (S). I found three brands that were suitable; the BCarry brand was 
clearly the best (L). However, it was quite expensive. I decided I needed to look around some more (S). I used my mobile phone to see whether I could find it elsewhere for cheaper (S). Indeed I did, at an online retailer called e-Babes (F). I bought BCarry from e-Babes at a $40 \%$ lower price! (C)"

Showrooming is an increasingly popular form of research shopping whereby the customer gathers information from a physical store but purchases online (Mehra et al. 2013). Figure 2B shows that the consumer starts with no information about baby carriers, so there are no lines to the left of search at Stage 1. After searching at BabyLand, three alternatives are identified and BCarry emerges as preferred. The consumer, however, is unhappy with the price and, therefore, the BCarry line is not thicker than the null option line. The consumer knows from previous experience that one can find products for less money on the Internet. She decides to search again using her mobile phone. The lines to the right of search in Stage 1 carry over to be the lines to the left of search in Stage 2. After this search, these utilities remain the same, but the consumer has found a new channel, the e-Babes website, which has the same brand for a less expensive price. This option is now preferred (thicker line) to buying in the store and is preferred to the null option. The customer purchases the brand from e-Babes.

\section{Story \#3: Channel Synergy and the Development of an Omnichannel Customer}

"I needed a new pair of casual pants. The Dockers brand had served me well. I knew the JC Penney store carried Dockers so I went there to try them on (S). They didn't fit. A J. Crew store had recently opened nearby (F) so I decided to look there (S). They didn't have Dockers although they had a store brand that I liked even better. However, they were an "Urban" style that didn't fit either. I went home and logged on the J. Crew website (S). There I found that the pants I liked came in "Classic" and "Regular" fit. I didn't know which one to order and didn't want to order over the Internet because of the shipping cost and hassle. So I went back to the store to ask what they could do (F). They told me I could order both the Classic and Regular fit right there in the store, via the manager's mobile device (F). I could return the pants that didn't fit to the store and they would return them for me (F). The pants arrived at my home and the Classic fit better. I went back to the store, and I was so happy with the service that rather than returning the Regular fit, I asked to exchange it for a Classic fit in a different color (C). The manager again used his mobile device to complete the transaction (F). I am happy with the two pants I bought from J. Crew. I've become more loyal to J. Crew (L) and am now using the physical store, website, and mobile channels (L). 
This is a richer story. The consumer goes through several search iterations and learns to become an "omnichannel" customer, a customer who integrates her or his decision process across channels. Stage 1 in Figure $2 \mathrm{C}$ shows that the consumer begins with high hopes for Dockers at JC Penney $-\mathrm{U}_{\text {Dockers,JCP,t }}$ is thicker than the null option; the customer expects to buy. However, upon searching at JC Penney, the customer finds that the pants do not fit and so the $\mathrm{U}_{\text {Dockers,JCP,t+1 }}$ line is not as thick as the null option. J. Crew has opened close by, so the customer searches there. The utility for Dockers at JC Penney carries forward at Stage 2. The customer finds a preferred alternative, the "Urban" style. Unfortunately, while $\mathrm{U}_{\text {Urban,JCS,t+3 }}>$ $\mathrm{U}_{\text {Dockers,JCP,t+3},}{ }^{1}$ the Urban/J. Crew combination is still not preferred over the null option. The customer returns home and searches the J. Crew website. He discovers in Stage 3 that the pants are available in Regular and Classic fits. However, which fit is best is still unknown, so while new lines appear for the regular and classic pants, they are not thicker than the null option. So the customer returns to the store. The customer orders the Regular and Classic fit using the manager's mobile device. In Stage 4, the customer finds that Classic fits best and is better than the null option. The customer is so happy he orders another pair. There are two key aspects to this process. One is the iterative aspect of searching, evaluating, and searching. An empirical model would have to represent this process. Second is what is learned from the experience. The consumer has learned that J. Crew offers great service, and that physical store, home-based Internet, and mobile can be used in a seamless fashion that defines the omnichannel customer.

\section{Research Questions}

\footnotetext{
${ }^{1}$ The S in JCS stands for store. This is to contrast with JCO, which denotes the J. Crew online channel (see Figure 2C).
} 
We now demonstrate the usefulness and applicability of our framework for generating research questions motivated by its four main elements: firm actions (F), search (S), choice (C), and learning (L). For each element, we identify one research question that we believe is particularly challenging and important to discuss in detail. We list five additional research questions motivated by our framework that due to space constraints we cannot discuss in detail. However, our purpose is to show that the framework can be used as a springboard for research. Undoubtedly, researchers can use the framework to identify additional topics.

\subsection{Firm Decisions}

The channel/assortment decision: The key to Story \#3 was J. Crew's decision to locate a new store (channel) in the consumer's location but not to carry a complete assortment. That is, the firm must decide which combinations of brand (b) and channel (c) to make available. Channel selection and assortment decisions have been addressed separately by previous research. For example, Hsiao and Chen (2013) and Kumar and Ruan (2006) have addressed firms' channel decisions. Borle et al. (2005), Hoch et al. (1999), and van Herpen and Pieters (2002) provide insights on how consumers react to assortments. However, $U_{b, c}$ is a joint utility and almost certainly will not be separable in brand and channel attributes. For example, Thomas and Sullivan (2005) find that customer channel preference depends on the product category.

In making the channel/assortment decision, firms will have to account for the omnichannel customer. For example, the consumer in Story \#3 was willing to explore alternative varieties that were not carried in the store. The firm will also need to set prices, undoubtedly a key determinant of $U_{b, c}$ (Verhoef et al. 2007). Retailers face higher inventory costs in the brick-and-mortar channel than in the Internet channels. This facilitates price differentiation across channels. In 
summary, the firm needs to decide which brands to offer consumers within each channel. This will in turn give rise to crucial questions regarding price and inter-channel synergy. The consumer's joint utility structure, $U_{b, c}$, will determine the decision.

Additional research questions: The following research questions are also motivated by the firm

(F) portion of our framework:

- Is there a first-mover advantage in channel adoption by brands, and if so which brands benefit?

- How should manufacturers allocate funds between brand and channel development?

- Are channels and brands in power conflict and how does that impact brand/channel choice?

- How should a firm's channel design depend on the designs of its competition?

- How does a brand's exclusive availability in one type of channel enhance brand performance vs. availability in several types of channels?

\subsection{Consumer Search}

Trading off complexity versus convenience: A key value proposition of the multichannel environment is convenience, and search convenience is critical for consumers' channel choices (Frambach et al. 2007; Gensler et al. 2012; Verhoef et al. 2007). Yet, the delivered value proposition might be complexity. Clearly the number of $U_{b, c}$ combinations multiply as customers continue searching. Lee and Lee (2004) show that information overload can decrease customer satisfaction when customers use a single website. The issue is compounded when we consider several websites, bricks-and-mortar stores, and several brands. As a result, the customer may resort to simplifying heuristics (search only the Internet, search only two websites, or search one brand) that inhibit brand building and result in less thorough searches. Story \#1 depicted a customer who simplified things to searching on Amazon and searching no further. Stories $\# 2$ and \#3 depicted consumers who were willing to deal with the complexity of multiple channels and 
multiple brands. We clearly need to understand whether multichannel provides convenience or complexity to consumers, whether it is a segmentation issue, and how firms should manage it.

Other research questions: The following are additional research questions motivated by the $\mathrm{S}$ portion of our framework:

- In which channel does the customer initiate search? How does this vary by product category and how does it affect the subsequent process?

- Do channel characteristics (e.g., atmosphere) reduce brand search?

- Does the type of information searched for differ across channels?

- What determines whether a research shopper switches retailers in the process, e.g., searches on Firm A's website but purchases from Firm B's retail store?

- How does the customer assess the value of searching on an additional channel? Is it pricedriven or the desire to find the right brand?

\subsection{Consumer Choice}

Sequence of the brand/channel decision process: Our framework shows that the ultimate determinant of choice is $U_{b, c}$. But the final set of lines that appears in Figure 1 depends on the sequence by which customers decide on channels versus brands. For example, the customer may first decide on brand, and then search additional websites to find the best price. Or the consumer may search various websites to determine the best channel for purchasing a product, then use that channel to determine the brand. In addition, the process may be iterative, as shown by the learning feedback loop in Figure 1. The customer may narrow down to a few channels, then a few brands, then one channel, then one brand.

The sequence of channel and brand choices affects both retailers and manufacturers. If consumers first decide on brand, manufacturers need to ensure their brand is available in many channels. If consumers first decide on a channel, retailers have to ensure presence in channels. 
The sequencing of the brand/channel decision process is clearly important for both researchers and practitioners.

Other research questions: The following research questions also relate to consumer choice (C) in Figure 1:

- How does the brand choice process differ by channel, and the channel choice process differ by brand? $?^{2}$

- How do different needs affect the process through which brands or channels get chosen?

- What is the extent of forward-looking behavior in brand/channel choice?

- Which process is more affected by marketing interventions: brand or channel choice? How do marketing interventions affect brand choice differently for various channels?

- What is the role of social influence on brand/channel choice?

\subsection{Consumer Learning}

Evolution in the brand/channel decision process: Our framework posits that learning occurs and feeds back to subsequent searches and choices. The question is how this learning affects the evolution of the brand/channel decision process. There is evidence that both channel choice (Valentini et al. 2011) and brand choice processes evolve (Carpenter and Nakamoto 1989; Erdem and Keane 1996). If indeed these processes interweave, does the nature of this entanglement evolve? Firms may disrupt the channel choice process when they add channels, but does this disrupt the brand choice process as well? If so, manufacturers need to increase marketing to retain their share until the customer brand decision process settles down again.

Other research questions: Other research questions related to consumer learning $(\mathrm{L})$ are:

- How does the channel decision process affect brand loyalty?

\footnotetext{
${ }^{2}$ We thank an anonymous reviewer for suggesting this research question.
} 
- How does the customer decide when to stop searching?

- What happens when a brand habit collides with a channel habit?

- Does the consumer's channel/brand decision process change when a consumer changes his place of residence?

- How does channel design and customer experience affect customer post-purchase outcomes such as confidence?

\section{Methodological Approaches}

An important challenge to investigate the brand/channel choice process is how one can empirically study these phenomena. Two approaches are experimentation and statistical modeling.

Experimentation can be pursued in lab settings. For example, one of our research questions asks how different needs affect the channel/brand choice process. Consumers' needs could be manipulated and experiment participants could then choose channel and brand in a laboratory setting. A challenge would be to construct an offline channel in the lab, but with today's computing capabilities, this should not be insurmountable. Another approach is to use quasiexperiments. Avery et al. (2011) utilize a quasi-experiment to analyze the introduction of a new physical store. As in all quasi-experiments, we have to assume this introduction is exogenous to the consumer's decision of where to shop. The use of exogenous channel introductions and deletions (Konus et al. 2014) provides a promising avenue for examining channel/brand consumer decision-making.

Studying brand/channel choice is sure to lend itself to cutting edge econometrics. Forwardlooking models, e.g., Bayesian learning, would be particularly applicable. There would be important challenges, e.g., incorporating time constraints and an evolving consideration set, but clearly the brand/channel choice process requires the customer to look ahead (e.g., "What am I to gain from searching more?"). 
Procurement of data to estimate the models still remains a challenge. An ideal dataset would encompass customer-level data of brand and channel choice, including purchase as well as search, plus marketing actions received by each customer, over an extended period of time. Traditional scanner data come close to this ideal in terms of purchase, but do not include search. Online search data are available from sources such as comScore, but these may be limited in terms of offline search, not to mention offline purchase. A possible alternative is cross-sectional surveys (e.g., Verhoef et al. 2007). These query consumers on their search and purchase processes as related to both brand and channel choices, but they fall short when one wants to study dynamics. A final approach would be to combine different data sources. There have been many advances in "data fusion" that would be promising in the brand/channel context (Feit et al. 2013).

Another econometric issue would be specifying the utility function. Our framework merely poses the existence of $U_{b, c, t}$. But how should this utility be expressed? We could have an additive model $U_{b, c, t}=U_{c, t}+U_{b, t}$, but very likely there will be interactions between channel and brand. One way to handle this would be through a nested logit, but the question would then be, which decision is at the top of the nest? This relates to one of our key research questions, the sequence of the process. Ordinarily a nested logit model is agnostic with respect to sequencing, but perhaps if the choice set differs between search and choice (e.g., see Figures $2 \mathrm{~B}$ and $2 \mathrm{C}$ ), one could use the better fitting model (channel first vs. brand first) to provide evidence for sequence.

\section{Summary}

We have explored the potential for research that investigates the consumer's decision of where and what to buy, i.e., channel and brand choice. Previous research has studied these areas 
separately; studying them jointly should reveal an even more enlightening view of how consumers navigate through a world of a bewildering assortment of brands and now channels.

We developed a general framework that can be used to generate research ideas, as well as provide a starting point for executing these projects. The framework is utility-function based and encompasses four key components - firm decisions (F), consumer search (S) and choice decisions (C), and consumer learning (L). Our discussion of methodological issues points to challenges that suggest progress will be made through a multi-method approach, i.e., including laboratory experiments, quasi-experiments, surveys, and econometric models. Overall, brand/channel choice is a relevant, rich topic, with ample potential for methodological as well as substantive contributions. 


\section{References}

Ansari, Asim, Carl F. Mela, and Scott A. Neslin (2008). "Customer Channel Migration", Journal of Marketing Research, 45 (1), 60-76.

Avery, Jill, Thomas J. Steenburgh, John Deighton, and Mary Caravella. (2012). "Adding Bricks to Clicks: Predicting the Patterns of Cross-Channel Elasticities Over Time", Journal of Marketing, 76 (3), 96111.

Borle, Sharad, Peter Boatwright, Joseph B. Kadane, Joseph C. Nunes, and Galit Shmueli. 2005. "The Effect of Product Assortment Changes on Customer Retention." Marketing Science 24, no. 4: 616622.

Carpenter, Gregory S., and Kent Nakamoto. (1989). "Consumer Preference Formation and Pioneering Advantage", Journal of Marketing Research, 26 (3), 285-298.

Danaher, Peter J., Isaac W. Wilson, and Robert A. Davis. (2003). “A Comparison of Online and Offline Consumer Brand Loyalty”, Marketing Science, 22 (4), 461-476.

Dodds, William B., Kent B. Monroe, and Dhruv Grewal. (1991). "Effects of Price, Brand, and Store Information on Buyers' Product Evaluations", Journal of Marketing Research, 28 (3), 307-319.

Erdem, Tulin, and Michael P. Keane. (1996). "Decision-Making Under Uncertainty: Capturing Dynamic Brand Choice Processes in Turbulent Consumer Goods Markets", Marketing Science, 15 (1) 1-20.

Feit, Eleanor McDonnell, Pengyuan Wang, Eric T. Bradlow, and Peter S. Fader. (2013). "Fusing Aggregate and Disaggregate Data with an Application to Multiplatform Media Consumption," Journal of Marketing Research, 50 (3), 348-364.

Frambach, Ruud, Henk C. A. Roest, Trichy Krishnan. (2007). "The Impact of Consumer Internet Experience on Channel Preference and Usage Intentions Across the Different Stages of the Buying Process," Journal of Interactive Marketing, 21 (2), 26-41.

Gensler, Sonja, Peter C. Verhoef, and Martin Böhm. (2012). “Understanding Consumers' Multichannel Choices across the Different Stages of the Buying Process;" Marketing Letters, 23 (4), 987-1003.

Guadagni, Peter M., and John D.C. Little. (1983). “A Logit Model of brand Choice Calibrated on Scanner Data", Marketing Science, 2 (3), 203-238.

Hoch, Stephen J., Eric T. Bradlow, and Brian Wansink (1999). "The Variety of an Assortment," Marketing Science, 18 (4), 527-546.

Hsiao, Lu and Ying-Chu Chen. (2013). "The perils of selling online: Manufacturer competition, channel conflict, and consumer preferences," Marketing Letters, 24 (3), 277-292.

Jerath, Kinshuk and Z. John Zhang. (2010). "Store Within a Store," Journal of Marketing Research, 47 (4), 748-763.

Konus, Umut, Peter C. Verhoef, and Scott A. Neslin. (2014). "The Effect of Search Channel Elimination on Purchase Incidence, Order Size and Channel Choice," International Journal of Research in Marketing, 31 (1), 49-64.

Kuehn, Alfred, and A.C. Rohloff. (1967). "Evaluating Promotions Using A Brand Switching Model”, in Patrick J. Robinson (ed.), Promotional Decisions Using Mathematical Models, Reading, MA: Allyn and Sons, pp. 50-85. 
Kumar, Nanda and Ranran Ruan. (2006). "On manufacturers complementing the traditional retail channel with a direct online channel," Quantitative Marketing \& Economics, 4 (3), 289-323.

Lee, Byung-Kwan and Wei-Na Lee (2004). "The Effect of Information Overload on Consumer Choice Quality in an On-Line Environment”, Psychology and Marketing, 21 (3), 159-183.

Mehra, Amit, Subodha Kumar and Jagmohan S. Raju. (2013). "Showrooming' and the Competition between Store and Online Retailers”, Working Paper, Indian School of Business.

Ratchford, Brian T. (1982). "Cost-Benefit Models for Explaining Consumer Choice and Information Seeking Behavior”, Management Science, 28 (2), 197-212.

Russell, Gary J. (2014). "Brand Choice Models", in Russell Winer, Scott A. Neslin (eds.), History of Marketing Science, (forthcoming), Now Publishers.

Thomas, Jacquelyn S., and Ursula Y. Sullivan. (2005). "Managing Marketing Communications with Multichannel Customers", Journal of Marketing, 59 (4), 239-251.

Van Herpen, Erica, and Rik Pieters. (2002) "The Variety of an Assortment: An Extension to the AttributeBased Approach." Marketing Science, 21 (3), 331-341.

Valentini, Sara, Elisa Montaguti, and Scott A. Neslin. (2011). "Decision Process Evolution in Customer Channel Choice", Journal of Marketing, 75 (6), 72-86.

Verhoef, Peter C., Scott A. Neslin, and Björn Vroomen. (2007). "Multichannel Customer Management: Understanding the Research-Shopper Phenomenon", International Journal of Research in Marketing, 24 (2), 129-148. 
Figure 1

Framework for Studying Brand/Channel Choice

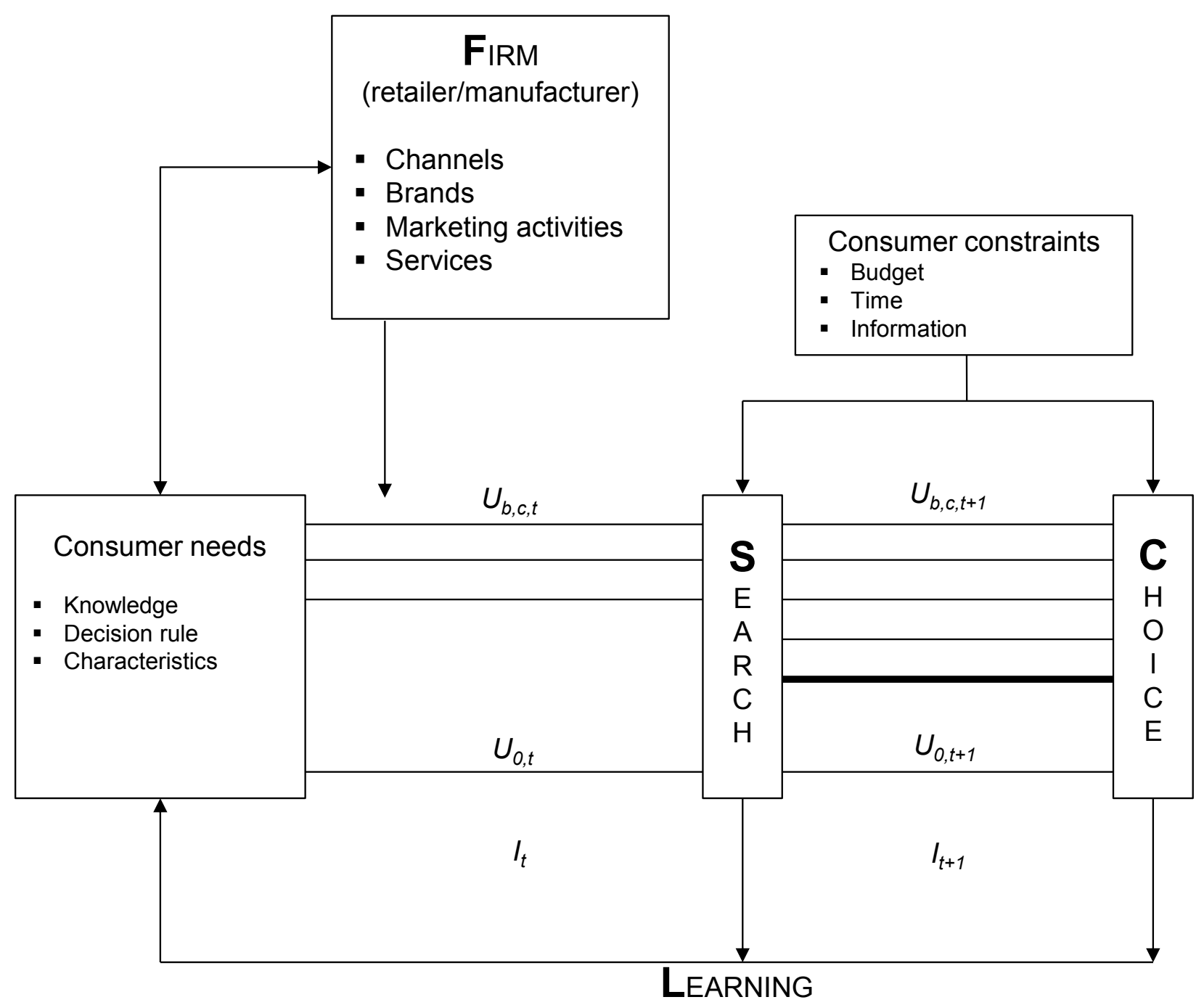

Note: After a consumer recognizes a need, she starts with an information set $\left(I_{t}\right)$, i.e., she is aware of various brand/channel combinations that deliver a certain utility $\left(U_{b, c, t}\right)$ including the null option $\left(U_{0, t}\right)$. The thickness of the lines represents the preference of the consumer. The information set is influenced by firms $(F)$, i.e., retailers and manufacturers. The consumer starts searching $(S)$ and updates her knowledge (L). This yields a new information set $\left(I_{t+1}\right)$. Search and choice $(C)$ are affected by potential consumer constraints. Finally, the consumer chooses the brand/channel combination that offers the highest utility (thickest line before choice is made). After the choice is made, the consumer updates her knowledge for use as future needs arise $(L)$. 
Figure 2

\section{Examples Using the Framework}

Figure 2A: Purchasing a Book at Amazon

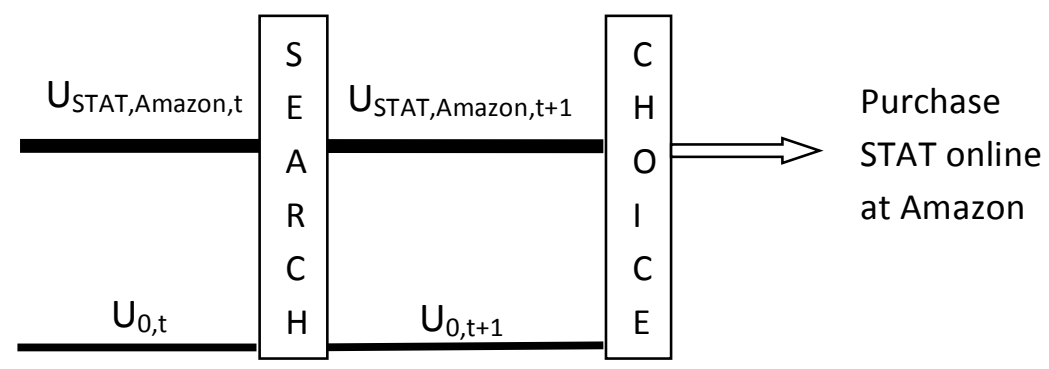

Figure 2B: Showrooming

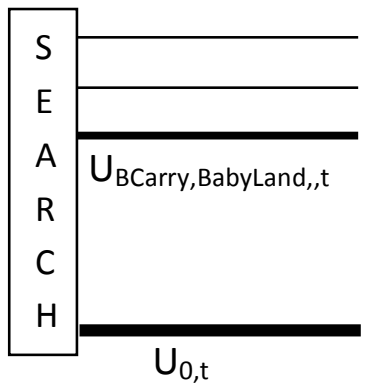

1. Visit to BabyLand

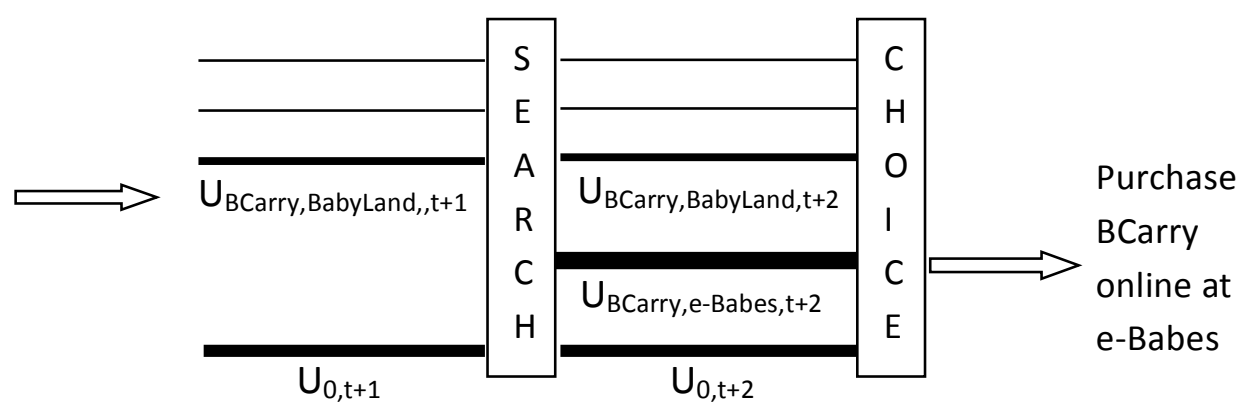

2. Finding the brand for cheaper at e-Babes. 
Figure 2C: Channel Synergy and the Development of an Omnichannel Customer

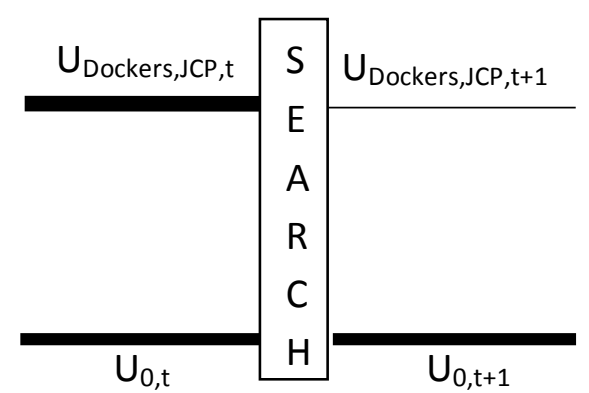

1. Visit JC Penney store

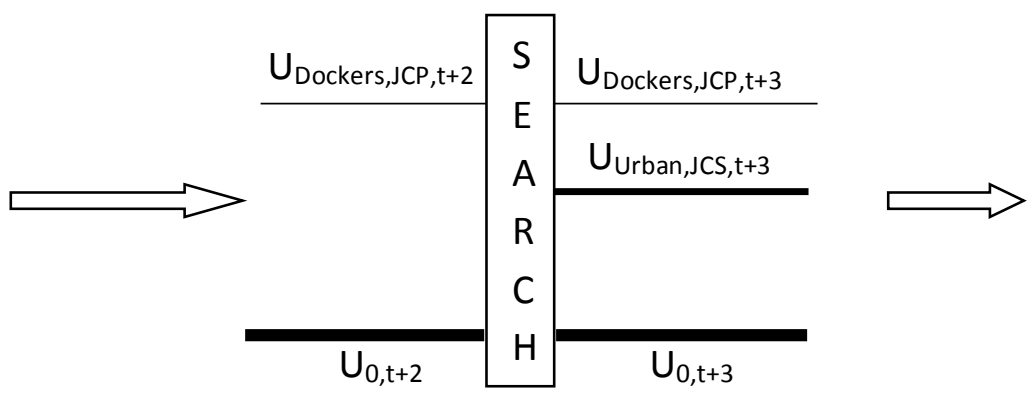

2. Visit J. Crew store
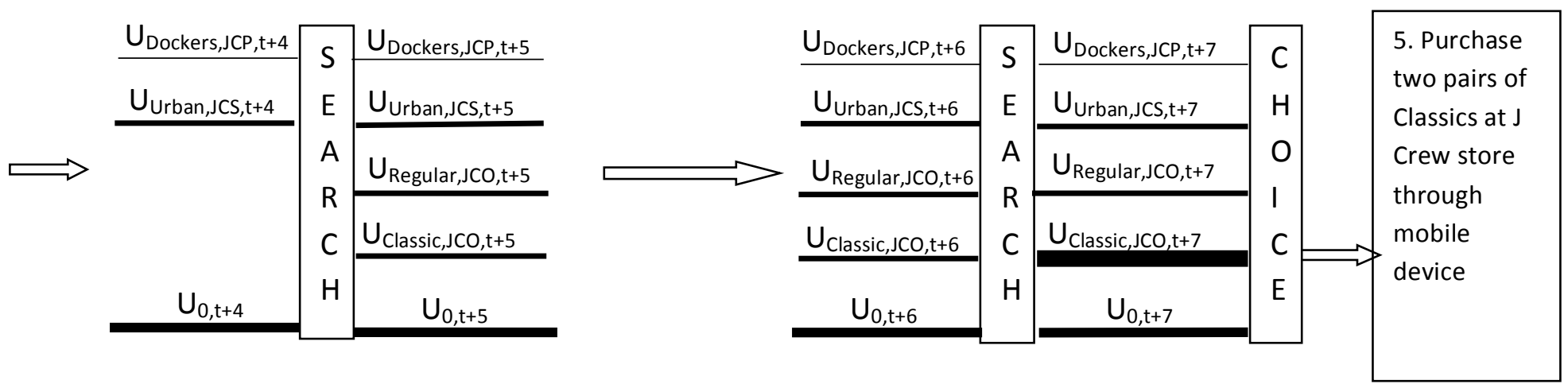

3. Visit J. Crew website

4. Order Classic and Regular from website using mobile device in store. 